\title{
The Impacts of Customer Characteristics on Innovation Resistance in Using Face Recognition Payment Systems: An Empirical Study
}

\author{
Lin-Lin Zhang ${ }^{1}$, Ha Kyun Kim ${ }^{2}$ \\ ${ }^{1}$ Graduate School of Information Systems, Pukyong National Univ., 45, Yongso-ro, \\ NamGu, Busan, China \\ ${ }^{2}$ Division of Business, Pukyong National Univ., 45 Yongso-ro, NamGu Busan, \\ Korea \\ lovelife_zll@hotmail.com,kimhk@pknu.ac.kr
}

\begin{abstract}
With the unfolding of the fourth industrial revolution, the combination of $5 \mathrm{G}$, big data, artificial intelligence, cloud computing and other technologies has become the basis for innovation in many industries. Within the financial operations of various industries, the payment services undergone vast changes after the application of new technology. With the popularity of smart phones, mobile payment has become the main payment method, gradually replacing cash payment and bank card payment. In order to ensure the security of the payment process, users need to enter a password for identity verification, and later for a more secure and convenient identity verification, biometric technology was introduced. In the recent years, with the in-depth integration of various technologies, a more convenient payment method has been produced, that is, the face recognition payment.

Face recognition payment is a simple payment method based on the face recognition system. The user does not need cash, bank card and mobile phone when paying, and only needs to perform face recognition through the camera on the POS terminal to complete the payment. The whole process only takes a few seconds. Face recognition payment as a new payment method has attracted much attention. Many offline stores in China have cited this new type of payment. The first case of face recognition technology in China in 2020 has attracted the attention of the society. Although the face recognition market is developing rapidly, the laws and regulations related to it are not perfect. People have doubts about whether the collected facial information can be properly stored, and many people worry that face information can be collected without consent, and whether the personal information and privacy can be guaranteed in the future or not. The high cost is not the only reason that hinders the development of the face
\end{abstract}


recognition market. Different customers will have different attitudes towards innovation.

This article aims to study the impact of customer characteristics on innovation resistance and to explore the impact of innovation resistance on intention to use, which will help face recognition payment technology and products to better meet user needs, so as to achieve the effect of innovation diffusion. This article chose attitudes towards existing products, motivation, self-efficacy, innovation and perceived risk as customer characteristics. It conducted an online questionnaire survey on 123 Chinese users through the Chinese "WENJUANXING" online survey system, collected data through SPSS 22.0, and analyzed the said data using Smart PLS 2.0.

Keywords: Face recognition, customer characteristics, innovation resistance, intention to use.

\section{Introduction}

With the beginning of the fourth industrial revolution, 5G, artificial intelligence, Internet of Things, cloud computing, big data, machine learning and other technologies have gradually merged and become the technical foundation of various platforms. The combination of these new technologies has enabled various platforms to play a greater role and improve the convenience of people's lives. Today, it has become an era in which human society, the network world and the physical world are increasingly integrated.

The combination of the financial industry and ICT and other technologies has formed a new financial technology industry. People's lifestyles have undergone tremendous changes, especially payment methods have become more and more convenient. Later, with the popularization of smart phones and the emergence of mobile financial technology, mobile payments gradually replaced cash payments and bank card payments. This change is particularly significant in China. In addition, the convenience and efficiency of mobile payment has accelerated economic development, facilitated people's lives, and played an important role in special times. According to the "China Mobile Finance Report 2020", affected by COVID-19, the payment utilization rate increased by $49 \%$ compared to 2019.

When using mobile payment, in order to ensure the security of the payment process, users need to complete identity verification to complete the payment. The most common authentication methods are passwords and PIN codes. However, because passwords are easy to lose, and with the development of technology, passwords are also easy to be stolen, so its security is limited. Therefore, in order to ensure the security of payment, biometric technology is introduced in the authentication process. The introduction of this technology has greatly improved the convenience of personal identity verification in the mobile payment process (Moon, 2008). At the same time, due to the uniqueness and difficulty of tampering with biometric information, the security of identity verification has also been greatly improved. Among them, face recognition technology is one of the issues worthy of 
attention. The global face recognition market is expected to grow from US $\$ 3.2$ billion in 2019 to US\$7.9 billion in 2024, with a compound annual growth rate of 16.6\% (China Biometrics Used with Mobile devices industry Research Report, 2020).

China has developed rapidly in technological innovation in recent years. In 2017 , Alipay cooperated with KFC. The face recognition payment system was officially used in offline stores for the first time. Consumers only need to choose a good meal on the KFC self-service ordering machine, select "Alipay face recognition payment", and perform face recognition authentication. They enter the mobile phone number bound to the account, verify your identity again, and click Confirm to pay. The whole process only takes a few seconds. In 2018, Alipay officially launched its own face recognition payment product "QingTing". With the upgrade of the product, users can make payments without entering their mobile phone number after face recognition. Data shows that China's investment in face recognition technology peaked in 2017 to 2018, and entered a period of rational development after 2019. The reasons include high technology and high costs caused by software and hardware requirements (China Face Recognsition Industry Research Report, 2020).

However, in 2020, there have been cases of face recognition in China. A tourist in Hangzhou, China, needs to perform face recognition in the Wildlife World to enter the park. The tourist believed that this behavior was an abuse of face recognition technology, and Animal World sued the court and won. In addition, some residential areas require face recognition to lift access control, which has caused social controversy. There have also been cases of hotel cameras illegally collecting face information of guests. This is because the human face has its peculiarities. It is the exposed part of the human body, which is inconvenient to hide and change. Once the face information is leaked, it will face the risk of privacy leakage or economic loss.

Therefore, high cost is not the only factor hindering the growth of the face recognition market. This requires attention to the impact of customer characteristics on innovation resistance. When studying innovation resistance, Ram said that not all innovations will be accepted, so resistance to change is a normal response of customers (Viorel and Cecilia-Roxana, 2013).

Therefore, it is of great significance to study the intensity and relationship of various factors in customer characteristics to innovation resistance, and to study the influence of innovation resistance on intention to use. At present, there are few researches on the resistance of customer characteristics to the innovation research of face recognition payment, but it is meaningful to study which factor of customer characteristics has the strongest influence on innovation resistance. This can help face recognition payment to better meet user needs, so as to achieve the effect of innovation diffusion. 


\section{Theoretical Background}

\subsection{Face Recognition Payment System}

Simple payment is one of the most representative industries in the financial technology industry. With the development of science and technology, the financial technology industry has also developed rapidly, and people's payment methods have undergone major changes. Simple mobile payment means that users only need to perform online identity verification on their mobile devices, and they can easily complete online and offline payments without the need for credit cards and cash. The most widely used authentication method for identity verification is password authentication, but in a network environment, the authentication password is very easy to leak. Once the password is leaked, it will cause personal information or property loss. Therefore, in order to increase the security of identity verification, biometric technology that can identify the user's body information (such as fingerprints, iris, face, veins, etc.) has been introduced.

Face recognition technology collects static or dynamic face images through a camera, and then processes the collected images, analyzes the features of the face (including ears, nose, mouth, eyes, etc.) from the images, extracts feature points and saves it as characteristic data, and then compares the identified data with the stored database to determine whether it is the same person (Lee, 2018).

Face recognition payment is a combination of face recognition. When using face recognition to pay, consumers only need to face the camera on the POS terminal screen at the cash register, and the system will automatically take a photo, scan the consumer's face, then process the image and extract the data and information stored in the database. The comparison is performed to determine whether they are the same person, and after the identity verification is passed, the consumer clicks OK to deduct the payment from the interconnected payment account and complete the payment. The entire process only takes a few seconds to complete. The world's first face recognition payment system appeared in Finland in 2013.

At present, China's face recognition technology is mainly used in security and finance. In 2018, there were 61 million face payment users in China. With the payment platform actively promoting the development of face payment, it is expected to exceed 760 million in 2022 (Internet report, 2019).

\subsection{Customer Characteristics}

Shaul (2003) pointed out in his research that customers with different personalities will lead to different innovation resistance, that is, consumers with different personalities have different attitudes towards the same innovative products or services.

Therefore, the study of customer characteristics has a positive impact on innovative products or services.

The survey found that when some customers feel unfamiliar and uncertain about 
the changes of innovative products and services, they prefer to maintain the current stable state and existing habits, because the impact of innovative products or services on consumers is unfamiliar and uncertain, while the existing products and services are familiar and certain to consumers (Kamran and Kim, 2009). Because they have become accustomed to existing products or services and are satisfied with existing products or services, they have little interest or even resistance to innovative products. On the contrary, when dissatisfied with existing products, users will be more willing to try new products.

Motivation is an important field in psychology. It is a kind of psychological tendency or external driving force to make behavior reach a certain goal. Motivation also affects customers' attitudes towards innovative products. Motivation can be divided into intrinsic motivation and extrinsic motivation. Intrinsic motivation refers to the behavior that customers want to try due to factors such as curiosity, even if there is no external reward, regardless of the result, and that the behavior itself is interesting. Extrinsic motivation refers to consumers taking specific behaviors due to the influence of external factors such as discounts and material rewards (Yang and Shin, 2010). Due to different internal and external incentives, everyone has different motivations for using or not using innovative products.

With the development of society and the improvement of personal cognition, people's behavioral abilities have become stronger and stronger. The concept of self-efficacy was put forward by the famous American psychologist Bandura. He believed that self-efficacy refers to the ability of an individual to successfully complete a given task or behavior when technological or product innovation occurs. Specifically, it refers to whether the individual has the belief that the individual can mobilize the required intelligence, emotion and behavior when facing a specific task when completing a given task (Kim, 2019).

Innovation is a very important factor in whether consumers can accept innovative products or services. Si and Kyung (2013) believed that customer innovation refers to their willingness to try and accept new technologies or services before others. Innovation is one of the personal characteristics. It is the degree to which a person is open to innovative products and services, may not be affected by the outside world, accept innovative products spontaneously, have a certain sense of adventure, and can accept unknown results. Highly innovative people have a positive attitude towards new and uncertain products.

Eugenio and Roberto (2021) proposed perceived innovation risk in the psychological research on innovation resistance. Perceived risk is divided into subjective and objective, including financial risk, performance risk, physical risk, time risk and psychological risk. This article mainly studies the psychological risk as a characteristic of consumers. Psychological risk refers to the psychological discomfort caused by nervousness or worry after using a new product or new servic. When users accept innovative products, ideas, and services, they cannot accurately 
predict the results of such behaviors, resulting in anxiety or worry (Lee and Dalho, 2019). This sentiment will affect their choice and use of innovative products.

\subsection{Innovation Resistance}

In Ram's research on the innovation resistance model, it is believed that product or service innovation has changed the habits of users. Therefore, user resistance to innovation is normal, and resistance is not the opposite of innovation. In life, innovation and resistance often coexist. Therefore, it is very useful to understand innovation resistance. It is necessary to find out the reasons for innovation resistance and make improvements to allow more users to adopt innovative products. Ram's innovation resistance model pointed out that there are three factors that can make customers have an impact on innovation: perceived innovation characteristics, customer characteristics, and diffusion mechanisms. The study also pointed out that innovation resistance will vary depending on customer psychology. Innovation resistance refers to customers trying to maintain their previous state in the face of new changes (He and Zhao, 2017). Whether an innovative technology can succeed or not, innovation resistance plays an important role. What users resist is not necessarily innovative technology or the product itself, but innovative technology brings new changes in habits.

\subsection{Intention to Use}

Intention to use is a psychological decision made when an innovative product or service feels convenient, easy to use, and useful (Zhang et al., 2021). In other words, it can be defined as the possibility of using products or services in the future. In addition, according to previous studies, it was argued that personal characteristics, social characteristics, product characteristics, and corporate characteristics influence the intention to use services (Jeong, 2017). A large number of studies have shown that innovation resistance will directly affect the intention of use (Park et al., 2021; Jin and Lim, 2020). That is to say, when users have a resistance attitude towards new products, their willingness to use new products will decrease.

\subsection{Research Model and Research Hypothesis}

\subsubsection{Research model}

At present, there are few research on the resistance of customer characteristics to the research of face recognition payment innovation, but the research on the influence of various factors in customer characteristics on innovation resistance has very positive significance. Although there are only a few people who may be resistant to innovative products or services, the positive impact on improving products cannot be ignored. Therefore, this article chooses attitudes, motivations, self-efficacy, innovation and perceived risk towards existing products as variables. Based on the technology acceptance model and previous studies, this research 
explores the impact of user characteristics on the resistance to face recognition payment innovation, and examines the impact of innovation resistance on the willingness to use. The research model is based on changes in the technology acceptance model (TAM) and innovation resistance model. The construction model is shown in Figure 1.

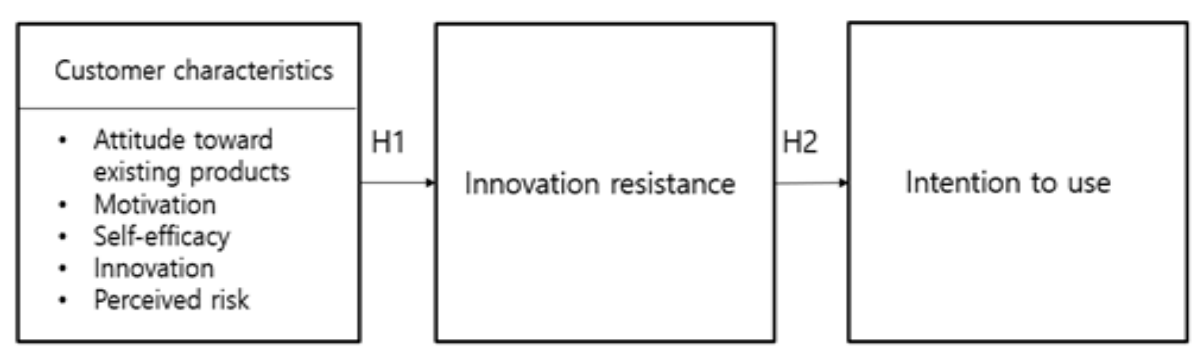

Fig. 1: Research model.

\subsubsection{Research hypothesis}

According to previous studies, there are many research on biometric authentication and simple payment, but not many on face recognition payment. As an innovative payment product, its research is of positive significance. When facing innovative products and services, the characteristics of consumers have an important impact on the adoption and resistance of innovations.

Based on previous research, this article chooses attitudes towards existing products, motivation, self-efficacy, innovation, and perceived risk as independent variables for previous products.

Mobile payment scanning QR codes and barcodes is widely used in China. Almost all stores can scan QR codes to pay. According to previous research, when consumers are more satisfied with the previous products, the more innovative resistance to new products will be, thus, the hypothesis below.

H1-1: Customer attitudes towards existing products have a positive $(+)$ impact on innovation resistance.

Similarly, when consumers are satisfied with the current status quo, their motivation to use innovative products will become lower. If external stimuli are not enough, consumers will lose interest in innovative products, thus, the hypothesis below.

H1-2: Customer motivation has a negative (-) impact on innovation resistance.

Previous studies have shown that self-efficacy is a user's confidence in completing a task. In other words, when a user feels that he can easily use an innovative product, his innovation resistance will become lower, thus, the hypothesis below.

H1-3: Customer self-efficacy has a negative (-) impact on innovation resistance.

When users are curious and eager to try innovative products, and can bear the 
unpredictable results they bring, innovation resistance will become lower. Thus, the hypothesis below.

H1-4: Customer innovation has a negative (-) impact on innovation resistance.

When users face the unknowns and uncertainties brought by innovative products, the stronger the perceived risk, the stronger the resistance to the new bed product, thus, the hypothesis below.

H1-5: Customer perceived risk has a positive (+) impact on innovation resistance. According to previous research, the user's innovation resistance is one of the important factors affecting the development of innovation. Therefore, the higher the customer's innovation resistance, the lower the willingness to use it. Thus, the hypothesis below.

$\mathrm{H} 2$ : Customer innovation resistance has a negative (-) impact on intention to use.

\section{Research Method}

The operation of each variable included in the research model designed in this paper is defined as follows (see Table 1).

Table 1: The operational definitions of variables

\begin{tabular}{|c|c|c|c|}
\hline \multicolumn{2}{|c|}{ Variables } & Operational definition & Reference \\
\hline \multirow{5}{*}{$\begin{array}{c}\text { Customer } \\
\text { characteristic }\end{array}$} & $\begin{array}{l}\text { Attitudes } \\
\text { towards } \\
\text { existing } \\
\text { products }\end{array}$ & $\begin{array}{l}\text { Satisfied with the existing products and } \\
\text { services, and willing to continue to use. }\end{array}$ & $\begin{array}{c}\text { Shaul, 2003; } \\
\text { Gao, } 2018\end{array}$ \\
\hline & Motiv-ation & $\begin{array}{c}\text { The mentality of performing an action } \\
\text { due to inner autonomy and external } \\
\text { stimuli. }\end{array}$ & $\begin{array}{l}\text { Yeon, 2011; } \\
\text { Ko and Lee, } \\
2019\end{array}$ \\
\hline & Self-efficacy & $\begin{array}{l}\text { Individuals can mobilize their } \\
\text { intelligence and behavior when facing } \\
\text { an unfamiliar innovative product to use } \\
\text { the product's belief. }\end{array}$ & $\begin{array}{l}\text { Koh et al., } \\
\quad 2019\end{array}$ \\
\hline & Innovation & $\begin{array}{l}\text { Innovation refers to the attitude that } \\
\text { consumers are willing to take risks and } \\
\text { actively try innovative products or } \\
\text { services than others. }\end{array}$ & $\begin{array}{c}\text { Si and } \\
\text { Kyung, } 2013\end{array}$ \\
\hline & Perceived risk & $\begin{array}{l}\text { Consumers are worried or anxious } \\
\text { about the unknown results after using } \\
\text { innovative products. }\end{array}$ & $\begin{array}{c}\text { Lee and } \\
\text { Dalho, } 2019\end{array}$ \\
\hline \multicolumn{2}{|c|}{ Innovation resistance } & $\begin{array}{l}\text { The behavior of users trying to } \\
\text { maintain the status quo in the face of } \\
\text { innovative products or services. }\end{array}$ & $\begin{array}{l}\text { Yoo and } \\
\text { Lee, } 1994\end{array}$ \\
\hline
\end{tabular}




\begin{tabular}{|c|c|c|}
\hline Intention to use & $\begin{array}{c}\text { Willingness or determination to use the } \\
\text { product or service }\end{array}$ & $\begin{array}{c}\text { Zhang et al., } \\
2021 \text {; Jeong, } \\
2017\end{array}$ \\
\hline
\end{tabular}

Table 2: Composition of questionnaire questions

\begin{tabular}{|c|c|c|}
\hline \multicolumn{2}{|c|}{ Variables } & Details \\
\hline \multirow{5}{*}{$\begin{array}{c}\text { Customer } \\
\text { characteristic }\end{array}$} & $\begin{array}{l}\text { Attitudes } \\
\text { towards } \\
\text { existing } \\
\text { products }\end{array}$ & $\begin{array}{l}\text {-Are you satisfied with fingerprint or password } \\
\text { authentication? } \\
\text { - You will pay with other authentication methods before } \\
\text { you pay with face recognition authentication? } \\
\text { - You don't feel the need to pay using face recognition? }\end{array}$ \\
\hline & Motivation & $\begin{array}{l}\text { - People around you are interested in face recognition } \\
\text { payments. } \\
\text {-You think it would be fun to pay using face recognition? } \\
\text { - You think it's easy and quick to pay using face } \\
\text { recognition. }\end{array}$ \\
\hline & $\begin{array}{c}\text { Self- } \\
\text { efficacy }\end{array}$ & $\begin{array}{l}\text { - If you can only use face recognition to pay, do you think } \\
\text { you have the ability to complete the transaction? } \\
\text {-If you were told how to use face recognition to pay, do } \\
\text { you think you would be able to learn to use it right away? } \\
\text { - Do you think you are quicker to accept new products and } \\
\text { services than others? }\end{array}$ \\
\hline & Innovation & $\begin{array}{l}\text { - Do you like to try new products or services before } \\
\text { anyone else? } \\
\text { - Do you enjoy challenging innovative products and can } \\
\text { handle the good and bad results? } \\
\text { - Are you interested in innovative products or services? }\end{array}$ \\
\hline & $\begin{array}{l}\text { Perceived } \\
\text { risk }\end{array}$ & $\begin{array}{l}\text { - You think face recognition payment is at risk of } \\
\text { disclosure of personal information and privacy. } \\
\text { - You worry that your face information will be tampered } \\
\text { with and misused. } \\
\text { - You worry that face information could be stolen by } \\
\text { hackers and cause financial losses. }\end{array}$ \\
\hline \multicolumn{2}{|c|}{ Innovation resistance } & $\begin{array}{l}\text { - You refuse to use it because you are worried about the } \\
\text { risk of paying for it. } \\
\text { - You are worried that the online environment is not safe } \\
\text { enough to pay for your face. }\end{array}$ \\
\hline \multicolumn{2}{|c|}{ Intention to use } & $\begin{array}{c}\text {-You have the intention of using face recognition to pay. } \\
\text { - You'll continue to pay with face recognition. } \\
\text { - You'll use it more often }\end{array}$ \\
\hline
\end{tabular}




\section{Empirical Analysis}

\subsection{Data Collection}

The investigation started on April 19 to April 23, 2021. According to the sample demographic data collected by the questionnaire, as shown in Table 3, among the respondents, 27 males accounted for $21.95 \%$, and 96 females accounted for $78.05 \%$. There were 11 people under 20 years old, accounting for $8.94 \%$; 55 people between 20 and 29 years old, accounting for $44.72 \%$; 48 people between 30 and 39 years old accounting for $39.02 \%$; 7 people between 40 and 49 years old, accounting for $5.96 \%$; and 2 people over 50 years old, accounting for $1.63 \%$. In terms of educational background, 3 students below high school accounted for $2.44 \%, 7$ students graduated from high school accounted for 5.69\%, 91 university graduates accounted for $73.98 \%$, and 22 masters or doctoral students accounted for $17.89 \%$. In terms of occupation, 30 students accounted for $24.39 \%, 12$ public institutions accounted for $9.76 \%, 2$ technical experts accounted for $1.63 \%, 7$ civil servants accounted for $5.69 \%$, and the other 72 accounted for $58.54 \%$.

Table 3: Demographic Characteristics $(n=123)$

\begin{tabular}{|c|c|c|c|}
\hline \multirow{2}{*}{ Gender } & Item & Frequency & Ratio (\%) \\
\cline { 2 - 4 } & Female & 27 & 21.95 \\
\hline \multirow{3}{*}{ Age } & $10 \sim 19$ & 96 & 78.05 \\
\cline { 2 - 4 } & $20 \sim 29$ & 11 & 8.94 \\
\cline { 2 - 4 } & $30 \sim 39$ & 55 & 44.72 \\
\cline { 2 - 4 } & $40 \sim 49$ & 48 & 39.02 \\
\cline { 2 - 4 } & Over 50 & 7 & 5.69 \\
\hline \multirow{4}{*}{ Education } & Below high school & 3 & 1.63 \\
\cline { 2 - 4 } & Graduated from high school & 7 & 2.44 \\
\cline { 2 - 4 } & University graduation & 91 & 5.69 \\
\cline { 2 - 4 } & Master or PhD & 22 & 73.98 \\
\hline \multirow{7}{*}{ Job } & Public institutions & 12 & 17.89 \\
\cline { 2 - 4 } & Technician & 2 & 9.76 \\
\cline { 2 - 4 } & Civil servant & 7 & 1.63 \\
\cline { 2 - 4 } & Student & 30 & 5.69 \\
\cline { 2 - 4 } & Other & 72 & 24.39 \\
\cline { 2 - 4 } & & & 58.54 \\
\hline
\end{tabular}

\subsection{Data Analysis}

This article uses Smart PLS 2.0 for analysis. In order to verify the reliability and validity of the measurement tool used, it was calculated that it met the measurement criteria through confirmatory factor analysis. Effective reliability should be Cronbach's Alpha 0.7 or higher. Validity is divided into focusing validity and discriminating validity. Concentration validity tests the factor load value, 
component reliability (CR) and variance extraction index value (AVE) of each factor. The validity period is divided into focused validity and differentiated validity. The factor load value, component reliability (CR) and variance extraction index (AVE) of each factor are tested for concentration validity.

In general, the factor loading value is 0.6 or more, the component reliability value is 0.7 or more, and the variance extraction index value is 0.5 or more to. As a result of comparing the square root of the variance extraction index value with the correlation coefficient, the variance extraction index value is greater than the vertical and horizontal correlation coefficient values, so there is no problem with the discriminant validity. In this study, before proceeding with the structural equation analysis for the reliability and validity analysis of the research model, the measurement model analysis was conducted first, as shown in Table 4.

Table 4: Reliability and internal consistency

\begin{tabular}{|c|c|c|c|c|c|}
\hline \multicolumn{2}{|c|}{ Variable name } & Factor Loading & AVE & CR & $\alpha$ \\
\hline \multirow{3}{*}{$\begin{array}{l}\text { Attitude toward } \\
\text { existing } \\
\text { products }\end{array}$} & ATE1 & 0.745 & \multirow{3}{*}{0.734} & \multirow{3}{*}{0.892} & \multirow{3}{*}{0.819} \\
\hline & ATE2 & 0.918 & & & \\
\hline & ATE3 & 0.898 & & & \\
\hline \multirow{3}{*}{ Motivation } & MOT1 & 0.887 & \multirow{3}{*}{0.850} & \multirow{3}{*}{0.944} & \multirow{3}{*}{0.912} \\
\hline & MOT2 & 0.943 & & & \\
\hline & MOT3 & 0.934 & & & \\
\hline \multirow{3}{*}{ Self-efficacy } & SEL1 & 0.909 & \multirow{3}{*}{0.811} & \multirow{3}{*}{0.928} & \multirow{3}{*}{0.883} \\
\hline & SEL2 & 0.916 & & & \\
\hline & SEL3 & 0.876 & & & \\
\hline \multirow{3}{*}{ Innovation } & INO1 & 0.933 & \multirow{3}{*}{0.835} & \multirow{3}{*}{0.938} & \multirow{3}{*}{0.902} \\
\hline & INO2 & 0.926 & & & \\
\hline & INO3 & 0.881 & & & \\
\hline \multirow{3}{*}{ Perceived risk } & PER1 & 0.928 & \multirow{3}{*}{0.892} & \multirow{3}{*}{0.961} & \multirow{3}{*}{0.940} \\
\hline & PER2 & 0.969 & & & \\
\hline & PER3 & 0.937 & & & \\
\hline \multirow{2}{*}{$\begin{array}{l}\text { Innovation } \\
\text { resistance }\end{array}$} & INR1 & 0.951 & \multirow{2}{*}{0.899} & \multirow{2}{*}{0.947} & \multirow{2}{*}{0.888} \\
\hline & INR2 & 0.946 & & & \\
\hline \multirow{3}{*}{ Intention to use } & USE1 & 0.929 & \multirow{3}{*}{0.883} & \multirow{3}{*}{0.958} & \multirow{3}{*}{0.934} \\
\hline & USE2 & 0.955 & & & \\
\hline & USE3 & 0.934 & & & \\
\hline
\end{tabular}

After confirming the enhanced validity of the research scale, correlation analysis was performed to determine the discriminative validity. If the AVE value obtained between each latent variable is greater than the coefficient of determination (the square of the correlation coefficient) of each latent variable, it is interpreted as a 
guaranteed discriminant validity. The analysis results show that, as shown in the following Table 5, the AVE value of all variables is greater than the square of the correlation coefficient of each variable, which shows that all variables have discriminant validity.

Table 5: Correlation and discriminant validity

\begin{tabular}{|c|c|c|c|c|c|c|c|c|}
\hline $\begin{array}{c}\text { Variable } \\
\text { name }\end{array}$ & AVE & ATE & INO & INR & MOT & PER & SEL & USE \\
\hline $\begin{array}{l}\text { Attitude } \\
\text { toward } \\
\text { existing } \\
\text { products }\end{array}$ & 0.734 & 0.857 & & & & & & \\
\hline Innovation & 0.835 & -0.205 & 0.914 & & & & & \\
\hline $\begin{array}{l}\text { Innovation } \\
\text { resistance }\end{array}$ & 0.899 & 0.708 & -0.235 & 0.948 & & & & \\
\hline Motivation & 0.850 & -0.336 & 0.595 & -0.450 & 0.922 & & & \\
\hline $\begin{array}{c}\text { Perceived } \\
\text { risk }\end{array}$ & 0.892 & 0.657 & -0.097 & 0.776 & -0.293 & 0.945 & & \\
\hline Self-efficacy & 0.811 & -0.272 & 0.708 & -0.408 & 0.674 & -0.235 & 0.900 & \\
\hline $\begin{array}{l}\text { Intention to } \\
\text { use }\end{array}$ & 0.883 & -0.410 & 0.644 & -0.459 & 0.821 & -0.285 & 0.709 & 0.940 \\
\hline
\end{tabular}

\subsection{Verification of The Structural Model}

In this study, Smart PLS was adopted as the data analysis method in consideration of the characteristics of the study such as theoretical robustness, the number of samples, and self-development of the questionnaire. If the R2 value is 0.26 or more, the degree of fitness is high, and if it is 0.26 to 0.13 , the degree of fitness is expressed as medium, and if it is less than 0.13 , the degree of fitness can be expressed as low. Innovative resistance (0.718) of the component value can be evaluated as high, and intention to use (0.211) can be evaluated as medium.

The research result model is shown in Fig. 2.

The model analysis results are as follows.

Hypothesis H1-1 'Customers' attitudes towards previous products have a positive (+) impact on innovation resistance." is statistically significant at the $95 \%$ significance level $(\mathrm{H} 1-1 ; \beta=0.300, \mathrm{t}=4.326, \mathrm{P}<0.05)$, so the hypothesis $\mathrm{H} 1-1$ is adopted. Therefore, the more customers prefer the previous product, the greater the innovation resistance to new product.

Hypothesis H1-2 "Customer motivation has a negative (-) impact on innovation resistance." is statistically significant at the 95\% significance level (H1-2; $\beta=-0.128$, 
$\mathrm{t}=2.140, \mathrm{p}<0.05)$ thus, the hypothesis $\mathrm{H} 1-2$ is adopted. Therefore, whether the customer is external or internal, the higher the motivation, the lower the innovation resistance to new product.

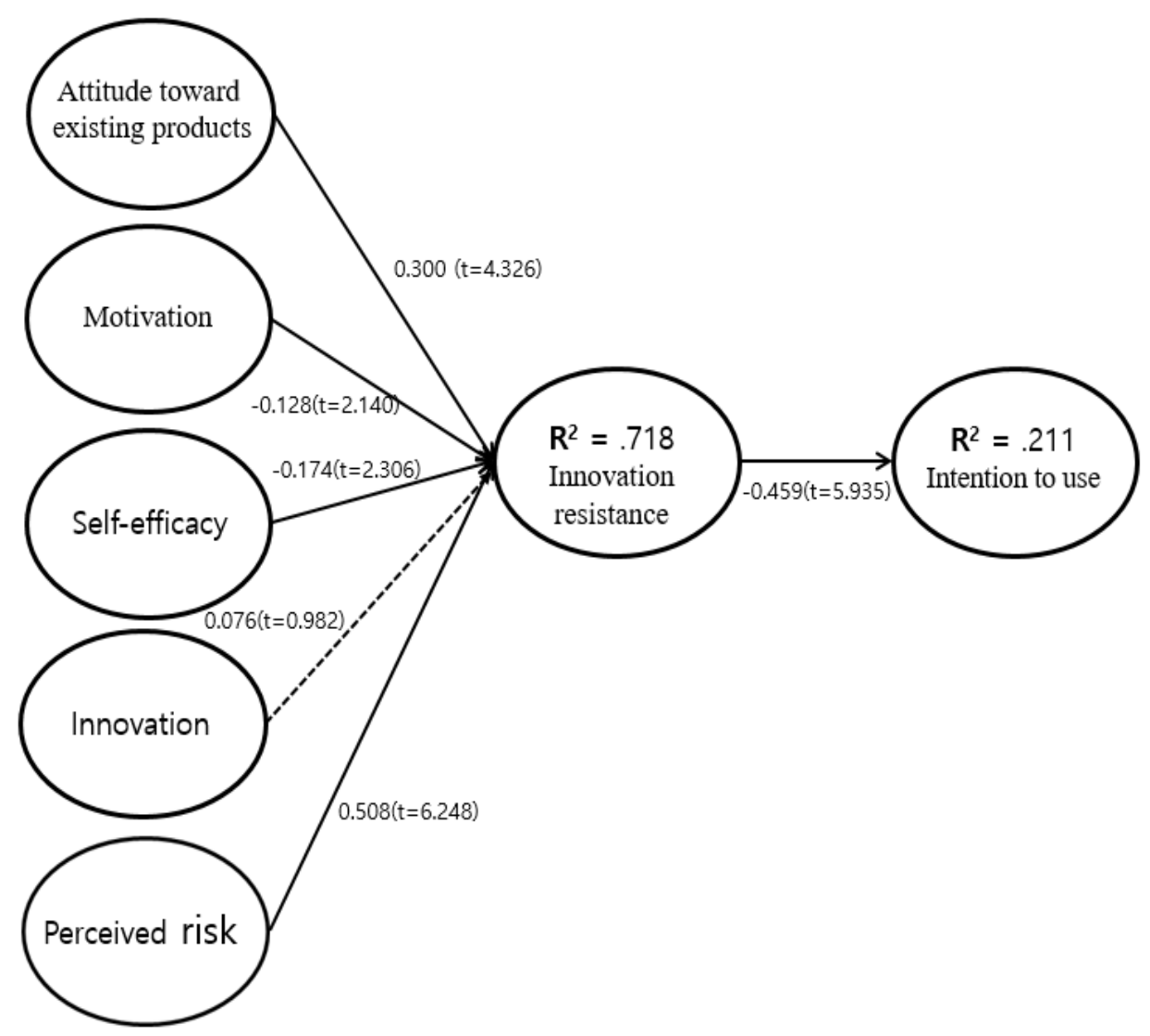

Fig. 2: The results of research model.

Hypothesis H1-3 "Customer self-efficacy has a negative (-) impact on innovation resistance." has a 95\% significance level $(\mathrm{H} 1-3 ; \beta=-0.174, \mathrm{t}=2.306, \mathrm{p}<0.05)$. It is statistically significant, so Hypothesis H1-3 is used. Therefore, the higher the customer's sense of self-efficacy for innovative products, the lower the innovation resistance.

Hypothesis H1-4 "Customer innovation has a negative (-) impact on innovation resistance." is not statistically significant at the 95\% significance level (H1-4; $\beta=0.076, t=0.982, p<0.05)$, so $\mathrm{H} 1-4$ is rejected.

Hypothesis H1-5 "Customers' perceived risk will have a positive (+) impact on innovation resistance." assuming statistical significance at a significance level of 95\% (H1-5; $\beta=0.508, \mathrm{t}=6.248, \mathrm{p}<0.05)$, so the hypothesis $\mathrm{H} 1-5$ is adopted. Among the customer's characteristics, the customer's perceived risk is an important 
factor in determining customer behavior. Therefore, the higher the perceived risk of customers paying for face recognition, the greater the resistance to innovation.

Hypothesis H2 "Customer innovation resistance has a negative (-) impact on intention to use." is statistically significant at the significance level of $95 \%(\mathrm{H} 2 ; \beta=-$ $0.459, \mathrm{t}=5.935, \mathrm{p}<0.05)$, so the hypothesis $\mathrm{H} 2$ was adopted. Therefore, the higher the customer innovation resistance, the lower the intention to use.

\subsection{Analysis of Test Result}

Analyzing the research hypothesis proposed in this study, the same result as Table 6 is obtained. Except for hypothesis H-4, all other hypotheses are accepted.

Table 6: Hypothesis Test Result Summary

\begin{tabular}{|c|c|c|c|c|l|}
\hline Cause variable & Result variable & $\begin{array}{l}\text { Path } \\
\text { coefficient }\end{array}$ & $\begin{array}{l}\text { T- } \\
\text { value }\end{array}$ & Result \\
\hline $\begin{array}{c}\text { Customer attitudes } \\
\text { towards previous } \\
\text { products }\end{array}$ & $\begin{array}{c}\text { Innovation } \\
\text { resistance }\end{array}$ & 0.300 & 4.326 & Accept \\
\hline H1-2 & Customer motivation & $\begin{array}{c}\text { Innovation } \\
\text { resistance }\end{array}$ & -0.128 & 2.140 & Accept \\
\hline $\mathrm{H} 1-3$ & Customer self-efficacy & $\begin{array}{c}\text { Innovation } \\
\text { resistance }\end{array}$ & -0.174 & 2.306 & Accept \\
\hline $\mathrm{H} 1-4$ & Customer innovation & $\begin{array}{c}\text { Innovation } \\
\text { resistance }\end{array}$ & 0.076 & 0.982 & Reject \\
\hline $\mathrm{H} 1-5$ & Customer perceived risk & $\begin{array}{c}\text { Innovation } \\
\text { resistance }\end{array}$ & 0.508 & 6.248 & Accept \\
\hline $\mathrm{H} 2$ & Innovation resistance & Intention to use. & -0.459 & 5.935 & Accept \\
\hline $\mathrm{t}=1.960^{* *}(\mathrm{P}<0.05)$ & \multicolumn{2}{|l}{} \\
\hline
\end{tabular}

\section{Conclusion}

With the development of science and technology, there are more and more innovative products, but research shows that not all innovative products will receive a positive response. Consumers will have resistance when facing innovation. In many cases, innovation and resistance exist at the same time. When innovative companies understand the reasons for consumer resistance, they can try their best to meet their needs, so as to achieve the effect of innovation diffusion, it is very necessary to study innovation resistance.

Face recognition payment as a new payment method has appeared in the public's field of vision, especially in China has been widely used. Due to its simple operation and convenient payment steps, many offline stores have cited this payment method. Although these financial technology companies are working hard to promote, they have not developed smoothly, because in addition to the 
requirements and costs of technology, software and hardware, apart from high, not all users recognize and accept this type of payment method.

Because face recognition payment uses face information as a verification method. Due to its uniqueness and irreplaceability, it provides a certain degree of security, but also due to the inconvenient hiding of the face and the particularity that it is not easy to modify, when the face information is when linking to a bank account, some people worry about whether their face information will be leaked and cause property damage. Therefore, this research mainly aims at Chinese users who have been generally exposed to face recognition payment, and conducts a sample survey through online questionnaires.

Based on the empirical analysis results, the following points are concluded.

First, the study found that in the process of innovation and diffusion of the face recognition payment system, customer innovation has no significant impact on innovation resistance. This is because the use of face recognition to verify identity is not the first time to verify identity through biometrics. Customers have become accustomed to using some physical features for identity verification.

Second, from the results, customer perceived risk has the greatest impact on innovation resistance. In particular, biometric technology is related to the customer's own characteristics. Faces, iris, fingerprints, voices, etc. are unique. Once the information is collected and abused, the user cannot change it. The massive collection and use of biological data make customers worry about privacy and personal information in the unregulated era of big data.

Third, the attitude towards previous products has a very high impact on innovation resistance. Especially in China, the usage rate of two-dimensional code payment and barcode payment in mobile payment is very high, through this new payment method, a "cashless society" has almost been realized. The QR code payment can be easily used in traditional markets and large supermarkets as long as there is a smart phone. Due to the convenience of this payment method and users have become accustomed to this method, the new face recognition payment will have certain resistance to innovation.

Fourth, customer motivation also has a positive impact on innovation resistance. When the customer's intrinsic or extrinsic motivation is relatively strong, the resistance to face recognition payment will become weaker.

Fifth, the stronger the customer's sense of self-efficacy, the weaker the innovation resistance. Because the operation of face recognition payment is very simple, most people can easily complete the payment, so the customer's resistance to it is weaker.

Sixth, innovation resistance plays an important role in usage intention. When users are more resistant to innovative products, they will postpone or refuse to use the product. Therefore, understanding innovation resistance has positive significance for the success of innovation or long-term development.

However, this study has the following limitations. 
According to previous research results, when faced with innovation, people of different ages, incomes or education levels respond differently to innovation resistance. This study is only a general study, and there is no differentiated study on people of different ages, incomes, and education levels. In order to more comprehensively summarize the research results, more abundant samples will be extracted in the future.

In addition, Ram stated in the innovation resistance model that the communication mechanism is also an important factor affecting innovation resistance. This article only studied Chinese users. Different communication mechanisms will also have different impacts on innovation resistance. In the future, we will compare samples under different communication mechanisms to provide a theoretical basis for the spread of face recognition payments in other countries.

In addition, it is necessary to regulate the face recognition market, accelerate the implementation of laws and regulations and the right to use big data, and reduce the worries of users in order to accelerate innovation and development.

\section{References}

Analysis of the market size and advantages and disadvantages of China's facial payment industry in 2019: 3D facial recognition technology will become the future trend. (2019).

China Biometrics Used with Mobile devices industry Research Report. (2020).

China Face Recognsition Industry Research Report. (2020).

Eugenio, G., and Roberto, C. (2021). Research on consumer risk perception and trust transmission between channels. International Journal of Smart Business and Technology, 9(1), 29-38.

Gao, X. (2018). A Study on Intention to Use Fintech Service: Focusing on Korean and Chinese Fintech Users", Keimyung University, Department of Trade, Ph.D. Thesis.

He, J., and Zhao Z. (2017). A study on innovation resistance of voice user interface with emphasis on mobile intelligent personal assistance service. The Kroea Contents Society Comprehensive Academic Conference Proceedings, 467-468.

Jeong, T. (2017). A study on the influence of characteristics of fin-tech system on customer acceptance: focused on mobile banking. Pusan National University, Department of Technology Business Policy, PhD thesis. 
Jin, Z., and Lim, C. K. (2020). A study on the influencing factors of customer satisfaction and continuous use intention in mobile payment service. International Journal of Smart Business and Technology, 8(2), 21-26.

Kamran, K., and Kim H. (2009). Factors affecting consumer resistance to innovation - a study of smartphones. Jonkoping University, Master Thesis within Business Administration.

Kim, S. (2019). User Characteristics on mobile OTT service adoption: moderating effect of usage frequency. Journal of the Korean Operations Research and Management Science Society, 44(4), 59-80.

Ko, M., and Lee, C. (2019). The effects of motivation of facebook on perceived ease of use, perceived usefulness, users' satisfaction, and continuous intention to use by applying technology acceptance model and self-determination theory: focused on students who apply for airline service management. Journal of Tourism and Leisure Research, 31(7), 379-393.

Koh, J., Kim, J., Kim, H., and Han, K. (2019). An empirical study on the effects of innovation resistance on the factors affecting the intention to accept blockchain in the finance sector. Journal of Digital Contents Society, 20(4), 783-795.

Lee, S. (2018). Biometric and surveillance: a study on the legal foundation and limit of identification through a facial recognition technology by investigation authorities. Law and Policy Research, 18(1), 171-197.

Lee, Y., and Dalho, S. (2019). The effect of reliability and innovation resistance on the switching value of fintech service. The Journal of Internet Electronic Commerce Research, 19(6), 75-88.

Moon, H. (2008). Face recognition: a survey. The HCI Society of Korea, 1683-1688.

Park, W. Y., Lee, S., Park, C., Jung, S., and Kim, H. (2021). The effect of service quality of internet insurance on intention to purchase online. International Journal of Smart Business and Technology, 9(1), 63-70.

Shaul, O. (2003). Resistance to change: developing an individual differences measure. Journal of Applied Psychology, 88(4), 680-693.

Si, N. L., and Kyung, Y. L. (2013). Determinants of eWOM behavior of SNS users with emphasis on personal characteristics, SNS traits, interpersonal influence, social capital. The Korean Journal of Advertising and Public Relations, 15(4), 273-315. 
Viorel, C., and Cecilia-Roxana, A. (2013). The customer resistance behavior towards innovation. Procedia Economics and Finance, 6, 457-465.

Yang, Y. S., and Shin, C. H. (2010). Innovation resistance of customer in accepting new technology - with emphasis on mobile phone touch interface technology. Archives of Design Research, 23(3), 37-52.

Yeon, J. R. (2011). Customers`Innovation Resistance Scale Development and Validation. The Korean Journal of Customer and Advertising Psychology, 12(1), 191-216.

Yoo, P. H., and Lee, S. H. (1994). A study on the innovation resistance of consumers in adoption process of new product - concentrated on innovation resistance model. Korean management review, 23(3), 217-250.

Zhang, L., Zhang, Y., and Kim, H. (2021). A study on the influence of customer characteristics on innovation resistance and intention to use in face recognition payment system. Journal of Advanced Researches and Reports, 1(3), 22-27. 